\title{
LATE ONSET HEREDITARY CATARACTS IN UPL RAT
}

\author{
Masayuki Tomohiro, Seiko Shinzawa, Kimie Yazawa, and Yoshitaka Aida \\ Upjohn Pharmaceuticals Limited, Tsukuba Research Laboratories \\ Shigekazu Uga
}

Department of Orthoptics and Visual Science, Kitasato University School of Allied Health Sciences

Aritake Mizuno

Department of Educational Health, Faculty of Education, Ibaraki University

Sadashige Sakuma

Department of Veterinary Pathology, College of Agriculture, University of Osaka Prefecture

\begin{abstract}
To identify initial changes and progression of late onset cataract of UPL (Upjohn Pharmaceuticals Limited) rat, cataractous lenses were evaluated ophthaimoscopically, histologically, and by Raman spectroscopy. At 2 to 4 weeks of age, intracellular vacuoles in the ends of the lens fibers and stratified epithelial cells were observed in the anterior suture of the lens. At 4 to 7 weeks of age, stratified epithelial cells and large vacuoles in lens fibers were present in the equator region. In the posterior cortex, small vacuoles were observed. Raman spectroscopic measurement indicated an increase in water content and the lens nucleus shift to the anterior. At approximately 7 weeks of age, mature cataracts, including rupture and liquefaction of lens fibers in the entire lens cortex, were present. In conclusion, the initial changes were observed in lens fibers at the anterior suture. Hydration of the posterior cortex might be correlated with lens opacification. (J Toxicol Pathol 9: 73 84, 1996)

Key words : Cataract, Rat, Raman spectra, Lens differentiation
\end{abstract}

\section{Introduction}

The UPL (Upjohn Pharmaceuticals Limited) rat is a new hereditary cataract model derived from the Sprague-Dawley rat ${ }^{1,2}$. The UPL rat cataracts are inherited as an autosomal dominant trait with a different age of expression in the homozygous, early onset (E-type) and heterozygous, late onset (L-type), states. The E-type rats have formed cataracts when their eyes open. Microphthalmos, microphakia, synechia, and buphthalmos are also observed. An abnormality of elongation of the lens fibers was observed in the E-type lens during fetal development (not published). Lens opacity in the L-type rats develops after birth as a vesicular opacity in the

\footnotetext{
友度雅之 新澤靖子 矢澤公恵 會田喜崇 宇賀茂三 水野有武 佐久間貞重

Accepted for publication: November 30, 1995

Mailing address : Masayuki Tomohiro, Upjohn Pharmaceuticals Limited, Tsukuba Research Laboratories, 23 Wadai, Tsukuba, Ibaraki 300-42, Japan.
}

anterior suture at approximately 3 weeks of age. Mature cataracts are present by 11 weeks of age ${ }^{1,2}$. The water content of the whole lens was determined to be increased after cataract development (not published). The water content of the lens was not increased before cataract development and it is not known whether an increase in water content was related to the formation of the cataract or the result of the cataract.

Laser Raman spectroscopy has been used to study the lens constituents in both normal and cataracterous lenses ${ }^{3-9}$. The use of laser Raman spectroscopy has the advantage of being able to study lens opacification, in situ, at the molecular level ${ }^{10-12}$.

In the present study, ophthalmoscopical and histological examination and laser Raman spectroscopic analysis were made to identify the initial changes and progression in cataract development in the UPL L-type rat. In addition, pathological features of the UPL L-type cataract were compared with other hereditary cataract models. 
Materials and Methods

\section{Animals}

The UPL rat strain was maintained as a closed colony at the Upjohn Pharmaceuticals Limited, Tsukuba Research Laboratories. L-type rats were produced by mating an E-type rat and a normal UPL rat (N-Type). The resulting litter had all L-type pups. Mating of two $\mathrm{N}$-type rats resulted in all $\mathrm{N}$ type pups $^{1,2}$.

\section{Ophthalmoscopic and histological examination}

The lenses of the L-type rats were examined using a direct ophthalmoscope and a slit lamp microscope and were classified into 5 stages (stage 0 , I, II, III, and IV) of cataract development.

The rats were killed by excessive amount of pentobarbital and the eyes immediately removed and placed in Davidson's fixative (ethanol 30\%, formalin $2 \%$, glacial acetic acid $10 \%$ ) for approximately 20 hours $^{13}$. The eyes were routinely processed and paraffin embedded blocks were sectioned and stained with hematoxylin and eosin. The slides were examined by light microscopy.

\section{Raman spectra measurements}

The lenses of L-type and N-type rats were examined by laser Raman spectroscopy at 3,4 and 6 weeks of age. The lenses were removed from the eyes, the length of the visual and horizontal axis of the lenses was measured using calipers and they were placed in cuvette cells filled with HEPES medium (pH 7.4, HEPES : $2.383 \mathrm{mg} / \mathrm{ml}$, sodium chloride : $7.96 \mathrm{mg} / \mathrm{ml}$, potassium chloride : $0.395 \mathrm{mg} / \mathrm{ml}$, dipotassium hydrogenphosphate : $0.228 \mathrm{mg} / \mathrm{ml}$, glucose : $0.991 \mathrm{mg} / \mathrm{ml}$, magnesium chloride : $0.102 \mathrm{mg} /$ $\mathrm{ml}$, calcium chloride, dihydrate: $0.25 \mathrm{mg} / \mathrm{ml}$ ). Raman spectra were measured at various positions along the visual and horizontal axis. Each Raman spectrum was evaluated at distances relative to the center of lens, which were calculated from actual measurement positions and the visual or horizontal axis length. The laser excitation source was an $\mathrm{Ar}$ laser $(514.5 \mathrm{~nm}, 400-500 \mathrm{~mW}$, model GLG 3200 , NEC, Tokyo). The R-1100 laser Raman spectrometer (JASCO, Tokyo) and a R-649 photomultiplier tube (Hamamatsu Photonics,
Hamamatsu, Japan) were used for the spectra measurements.

Results

\section{Ophthalmoscopic examination}

Figure 1 illustrates the lenses from UPL L-type rats at each stage of cataract development and Fig. 2 shows the ages at which each stage was observed. The lenses which did not have visible alterations were classified as stage 0 . The stage I change consisted of a small vesicular opacity in the anterior suture (Fig. 1A). Stage I cataracts were usually observed at 2 to 4 weeks of age but were coincident with eye opening in some L-type rats. Approximately $30 \%$ of the Ltype rats did not have a stage I cataract. These rats developed a slight superficial opacity in the equator region of the lens at 2 to 6 weeks of age (Fig. 1B) which was classified as a stage II cataract. Stage III cataracts consisted of severe equatorial opacity of the lens (Fig. 1C) and later, perinuclear opacity (Fig. ID). Stage III cataracts were observed at 4 to 7 weeks of age. The mature cataract, stage IV, was present at 5 weeks of age and older (Fig. 1E). The average age for stage IV cataract development was approximately 7 weeks.

\section{Histological examinations}

The lenses classified as stage 0 by clinical examination were histologically normal. Intracellular vacuoles were present in the end of the lens fibers in the anterior suture region of the stage I cataract (Fig. 3A). In addition, stratified epithelial cells and an irregular arrangement of the lens capsule were observed in the suture and equator region (Figs. $3 \mathrm{~A}$ and 3B). No abnormalities were observed in the cortex of the equator region. The lenses with stage II cataracts had markedly stratified lens epithelial cells, swelling of the lens fiber cells, and large vacuoles in the equator region (Fig. 3C). Nucleated cells were often present in the posterior subcapsular region. In stage III lenses, small vacuoles were present in the posterior cortex (Fig. 3D). Stratified epithelial cells and large vacuoles were also observed in the equator region. The stage IV lens had mature cataracts which histologically consisted of ruptured and liquefied lens fibers in the cortex (Fig. 3E). There 
Tomohiro, Shinzawa, Yazawa, et al

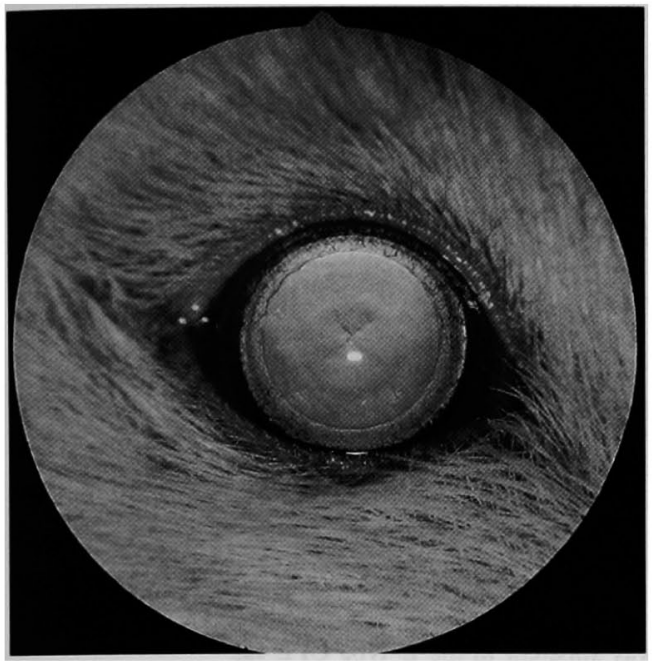

A

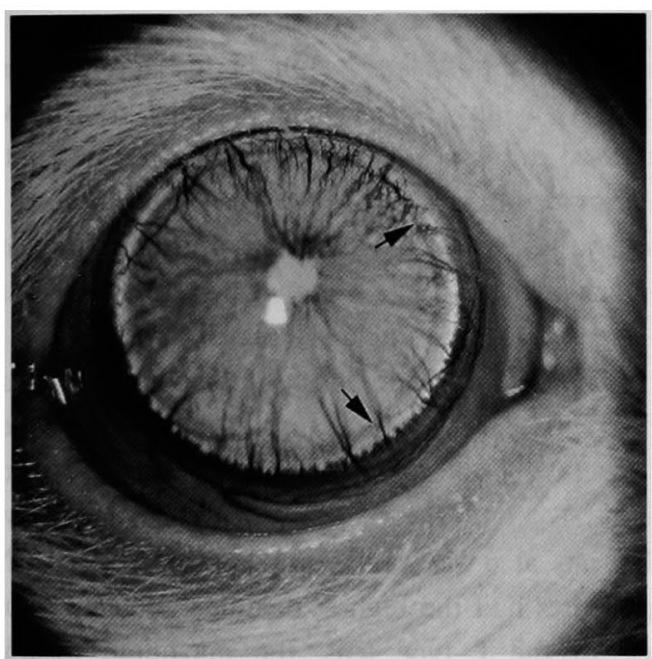

B

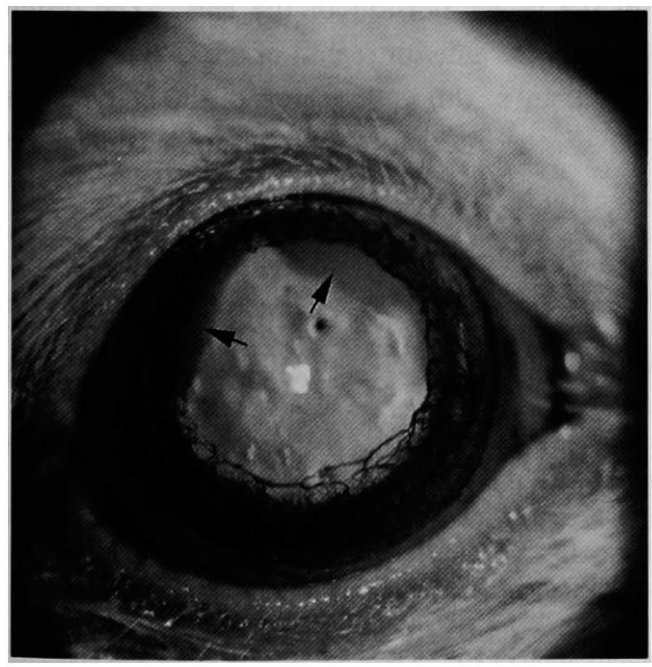

C

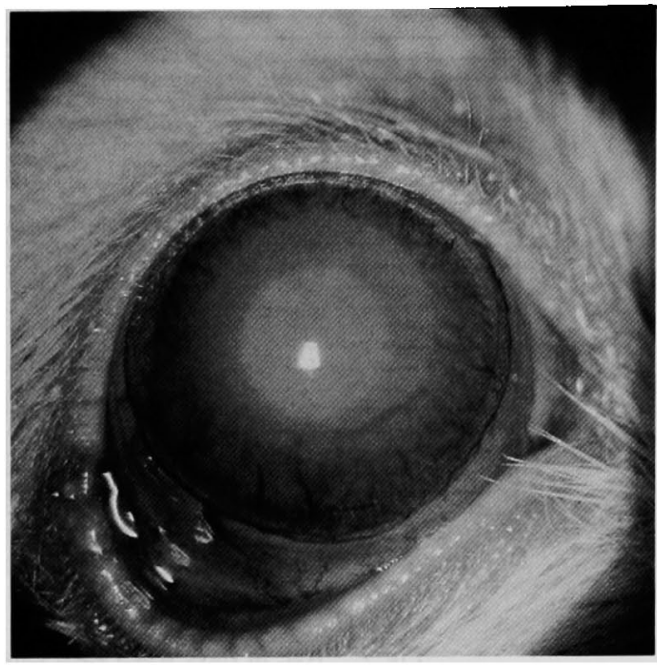

D

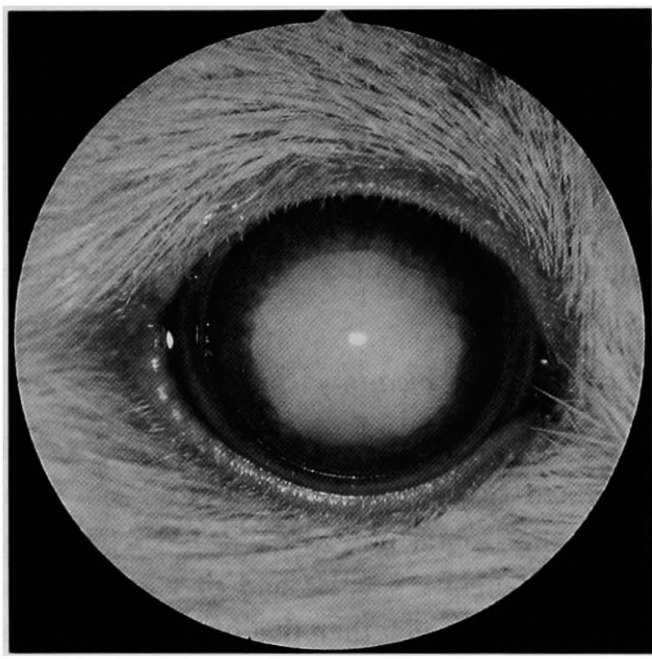

$\mathbf{E}$

Fig. 1. Cataract stages in the L-type UPL rat.

A. Stage I. Slight vesicular opacity in the anterior suture.

B. Stage II. Slight superficial opacity in the equator region (arrow).

C. Stage III. Severe opacity in the equator region (arrow).

D. Stage III. Perinuclear opacity.

E. Stage IV. Mature cataract. 

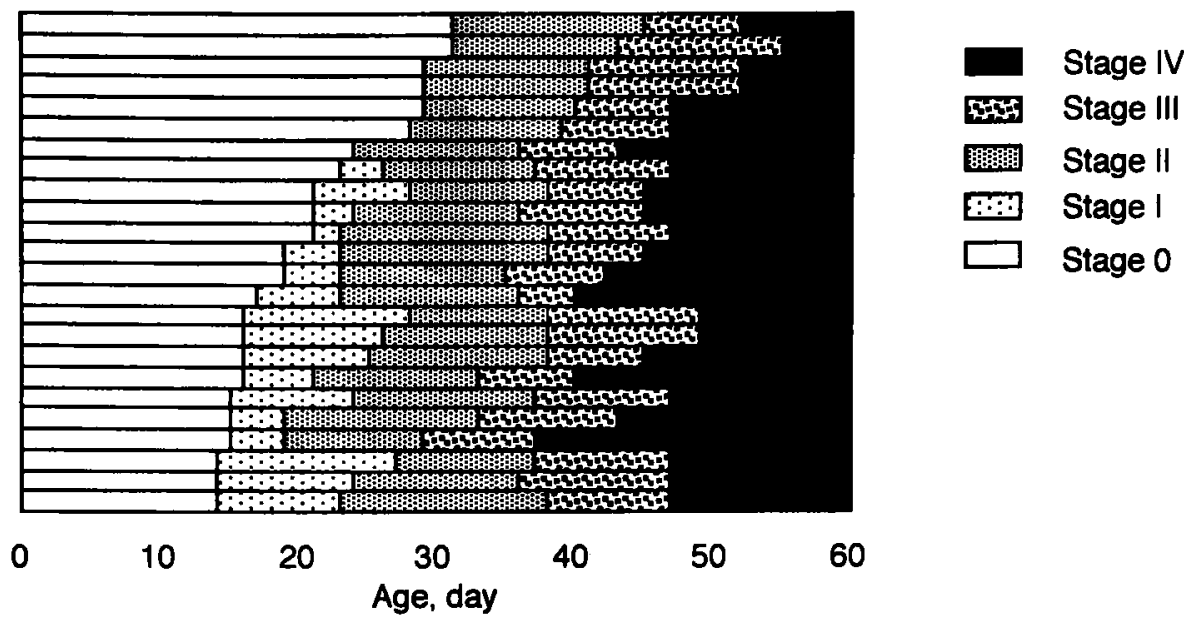

Fig. 2. Age in days when each cataract stage was apparent in the L-type UPL rat.

was no continuity between the affected lens fibers and the stratified epithelial cells. Rupture of lens fibers was observed in most of the cortex, although liquefaction was found mainly in the anterior subcapsular region (Fig. 3F). Lacunae of the lens epithelial cells were also present.

\section{Raman spectrum measurements}

Figure 4 shows the size of the lenses in the UPL $\mathrm{N}$-type and L-type rats. At 3 and 4 weeks of age, both the horizontal and visual axis of the L-type lenses were slightly smaller and at 6 weeks of age, were obviously smaller than that of the $\mathbf{N}$-type lenses.

The ratio of the intensity of the Raman bands at 3,390 and $2,935 \mathrm{~cm}^{-1}\left(I_{3390} / I_{2935}\right)$ indicates relative water content ${ }^{7,8.14}$. The ratios $\left(I_{3390} / I_{2935}\right)$ for the lenses of L-type and N-type UPL rats at 3, 4, and 6 weeks of age, are summarized in Figs. 5A and 5B. There were no differences in the water content of the anterior and posterior region of the $\mathrm{N}$-type lenses (Fig. 5A) at any age. However, water content was increased in the posterior region and decreased in the anterior region of the L-type lenses from 3 weeks of age and older. There was no difference in water content at the equator region when the L-type and $\mathrm{N}$-type rats were compared (Fig. 5B).

The ratio of the intensity of the bands at 510 and $495 \mathrm{~cm}^{-1}\left(I_{510} / I_{495}\right)$ is indicative of the relative content of disulfide bonds ${ }^{10,15,16}$. Figures $5 \mathrm{C}$ and $5 \mathrm{D}$ show the $I_{510} / I_{495}$ ratios in the lenses of L-type and $N$-type UPL rats at 6 weeks of age. The center of the Ntype lenses had the highest disulfide content. However, in the L-type lens, the maximum disulfide content was observed in the region slightly anterior from the center portion of the lens. The disulfide content in the anterior region of the L-type lenses was higher than in the same region of the $\mathrm{N}$-type lenses. There was no alteration of the disulfide content in the

Fig. 3. Histological features of the lens of the L-type UPL rat.

A. The suture region of the stage I lens at 2 weeks of age. There are vacuoles in the ends of the lens fibers (arrow) and stratified epithelial cells (arrow head). HE, $\times 80$

B. The equator region of the stage I lens at 2 weeks of age. Stratified lens epithelial cells and irregular arrangement of lens capsule are evident. $\mathrm{HE}, \times 40$

C. The equator region of the stage II lens at 5 weeks of age. Stratified lens epithelial cells, swelling of lens fiber cells (arrow), and large vacuoles are present. There are nucleated cells in the posterior region (arrow head). HE, $\times 40$

D. Stage III lens at 6 weeks of age. Small vacuoles are present in the posterior cortex (arrow). Stratified epithelial ceils and large vacuoles are also observed in the equator region. $\mathrm{HE}, \times 16$

E. Stage IV lens at 7 weeks of age. Marked rupture and liquefaction of lens fibers are observed in the lens cortex. HE, $\times 10$

F. The anterior subcapsular region of the stage IV lens (high magnification of $E$ ). There are lacunae of the lens epithelial cells (arrow). Marked rupture (R) and liquefaction (L) of lens fibers are also observed. $\mathrm{HE}, \times 50$ 
Tomohiro, Shinzawa, Yazawa, et al

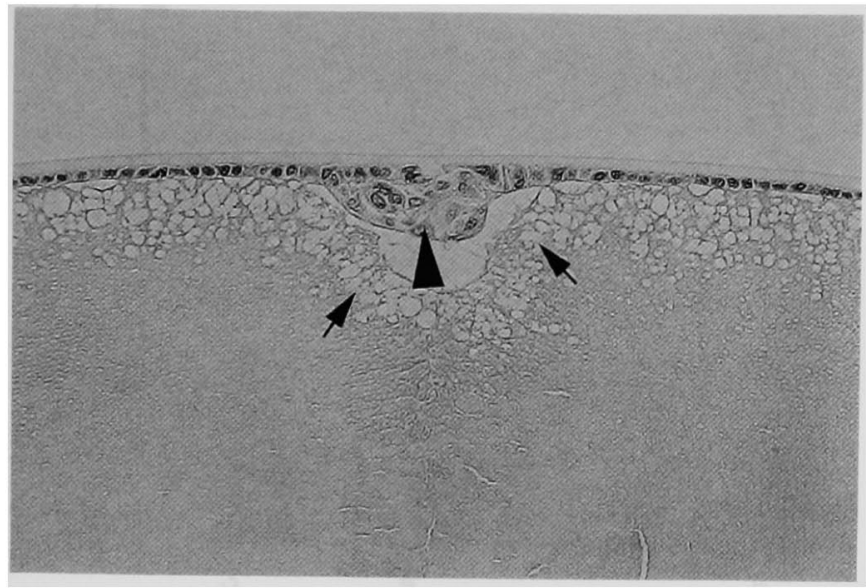

Fig. 3A.

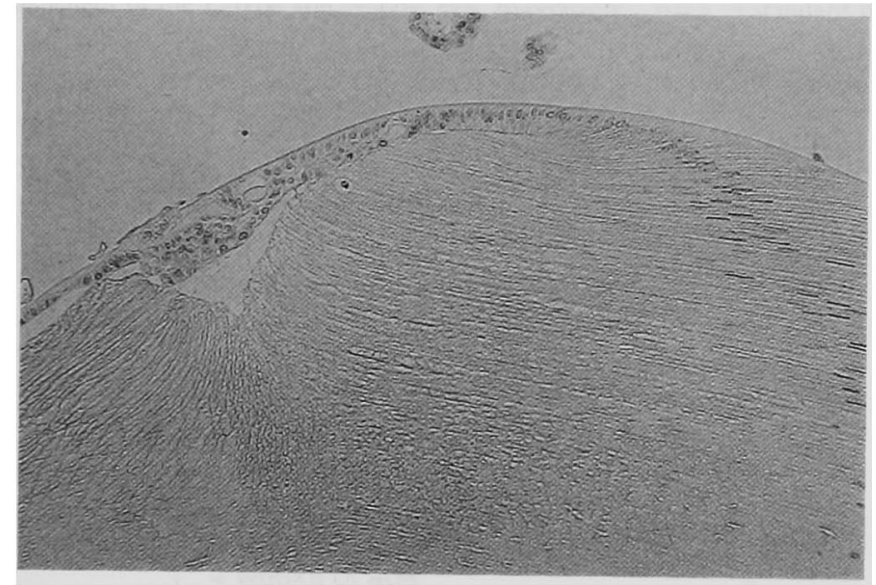

Fig. 3B.

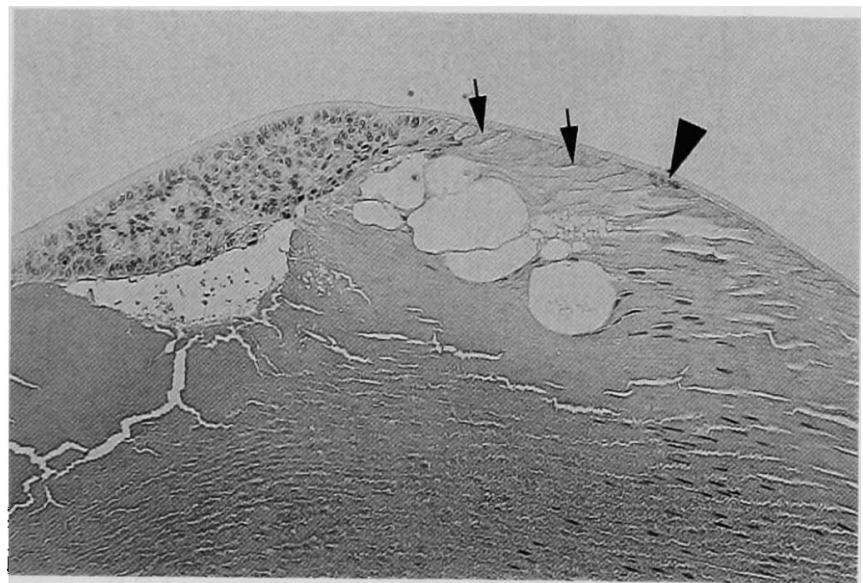

Fig. 3C. 


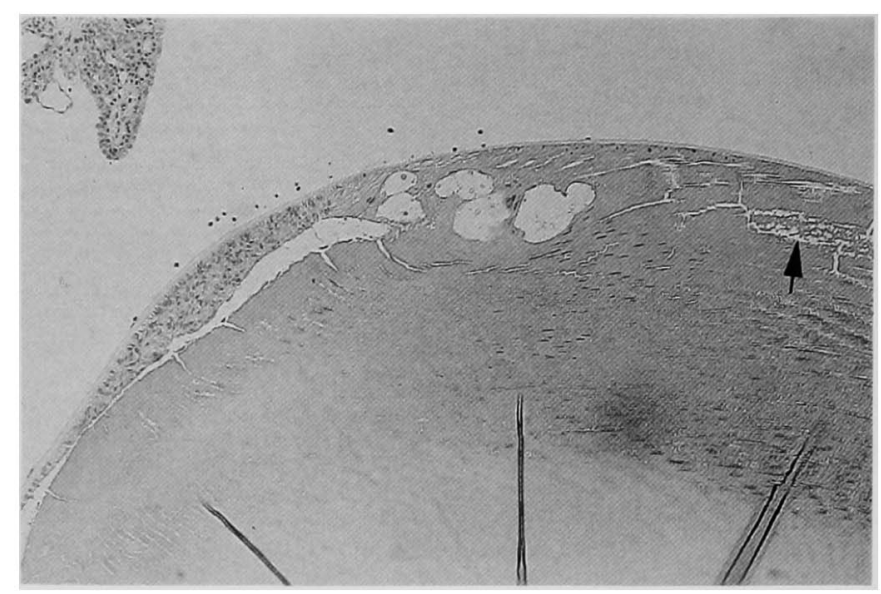

Fig. 3D.

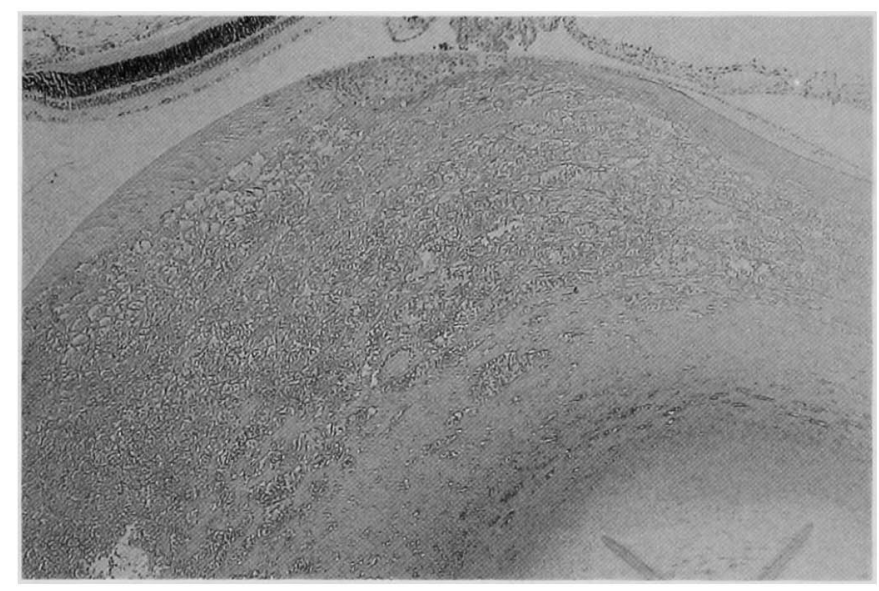

Fig. 3E.

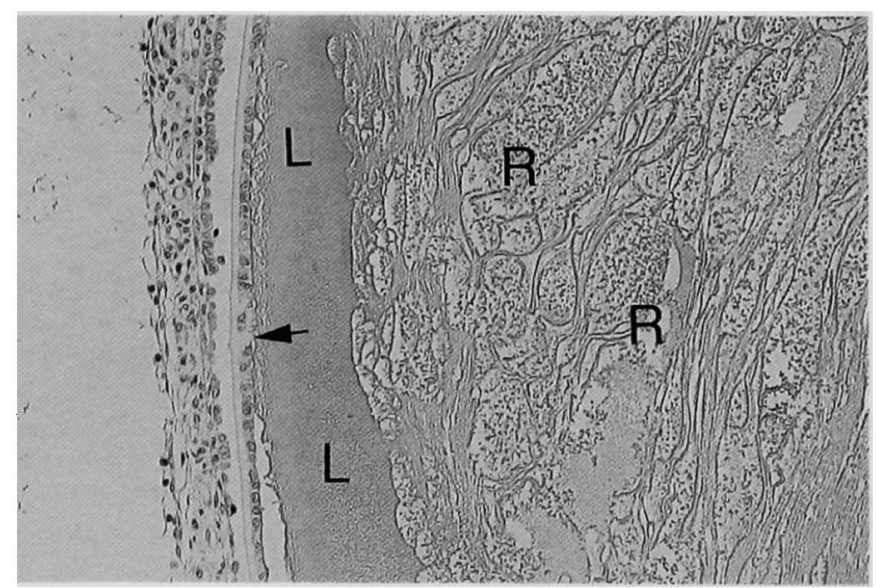

Fig. 3F. 


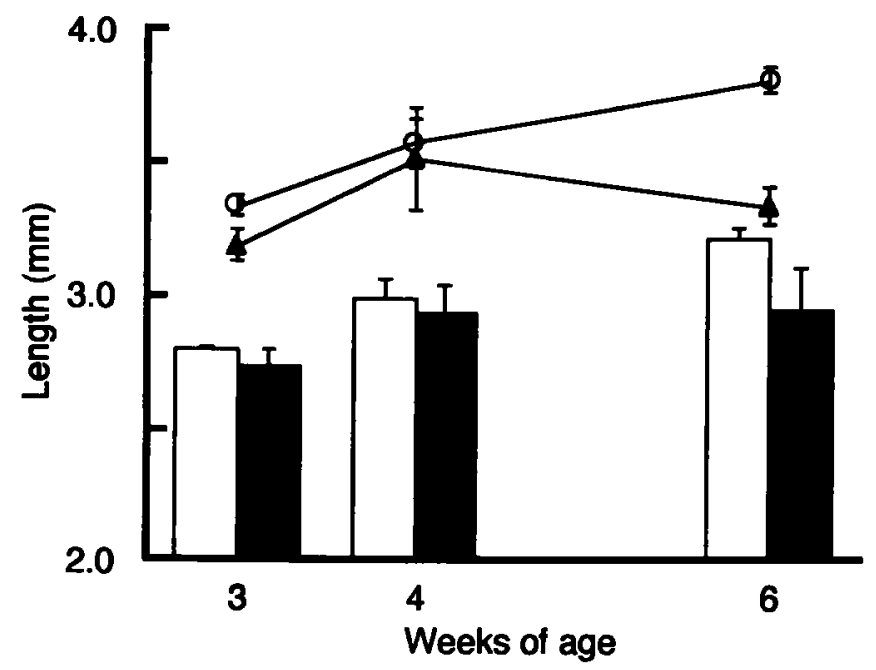

Fig. 4. The horizontal axis length of the L-type $(\Delta)$ and N-type (O) UPL rat. Black and white columns show the visual axis length of the $\mathrm{L}$-type and $\mathrm{N}$-type lens, respectively. $\mathrm{n}=5, \pm$ standard deviation.

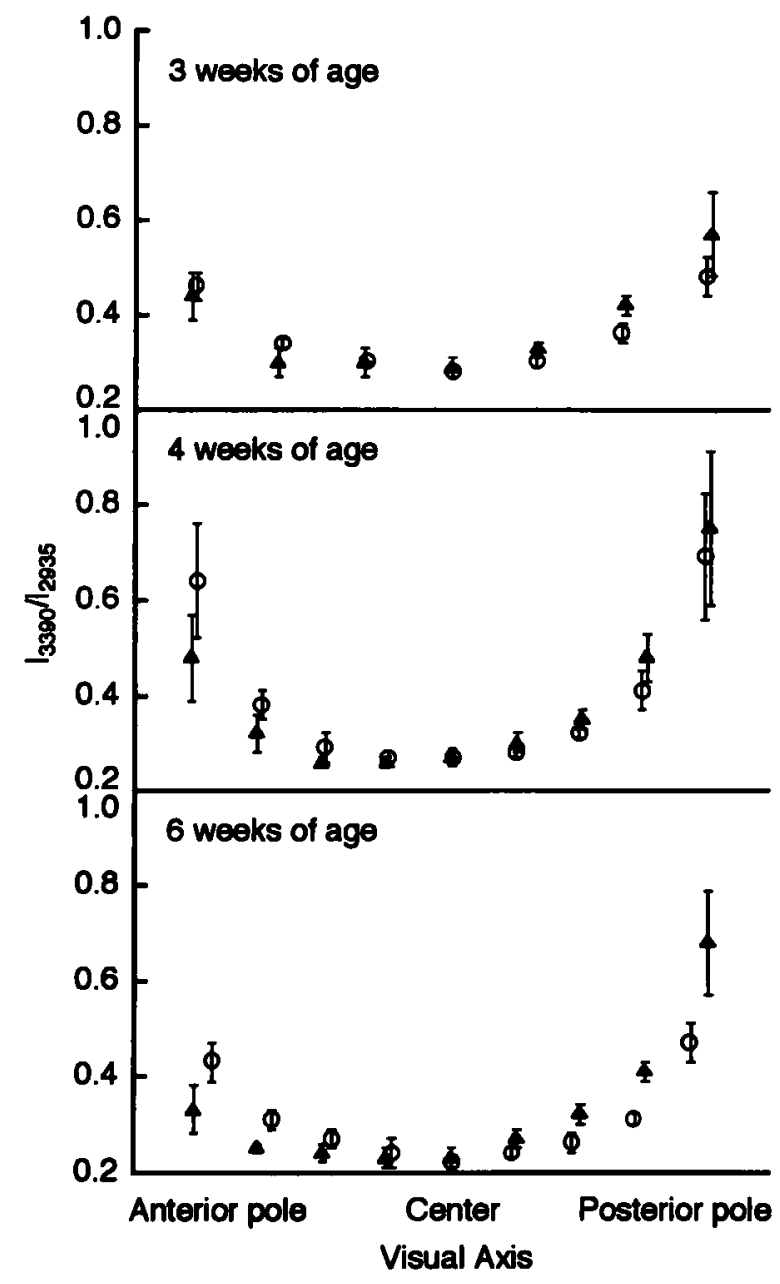

Fig. 5A. 


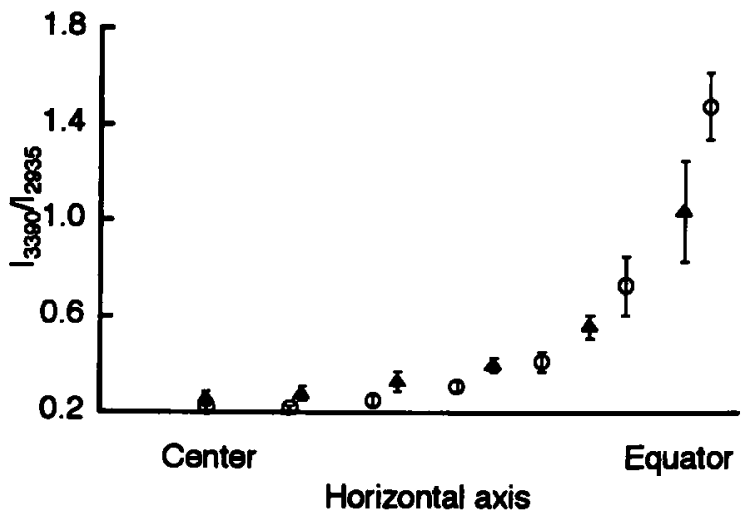

Fig. 5B.

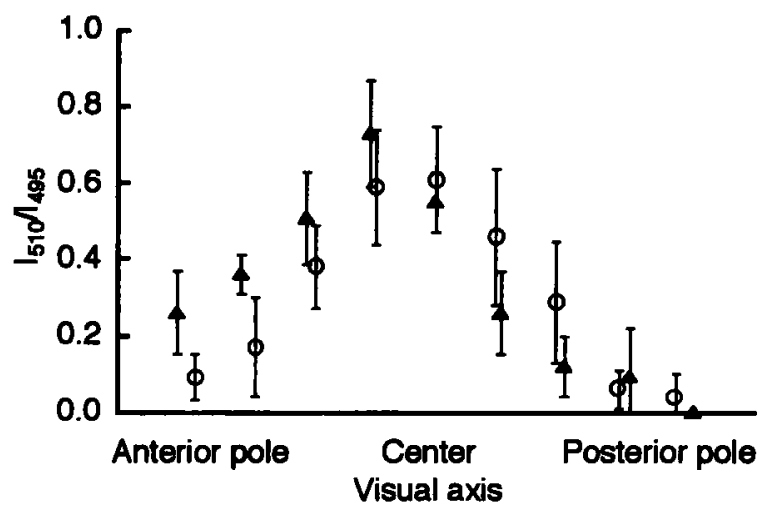

Fig. 5C.

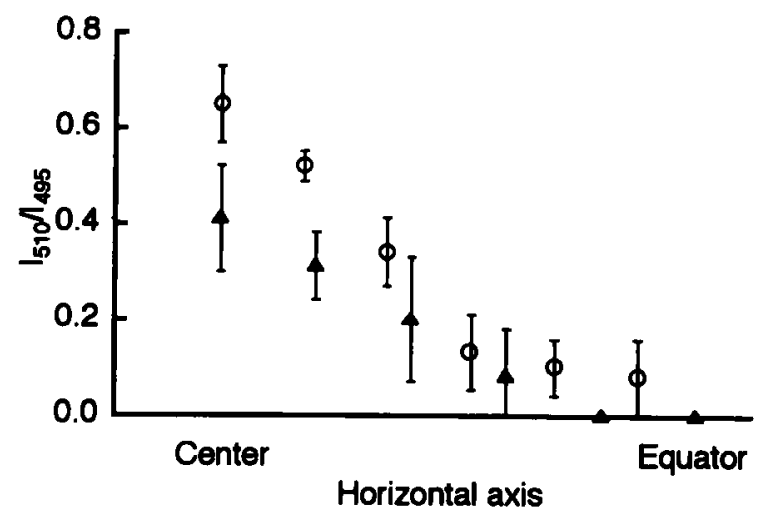

Fig. 5D. 


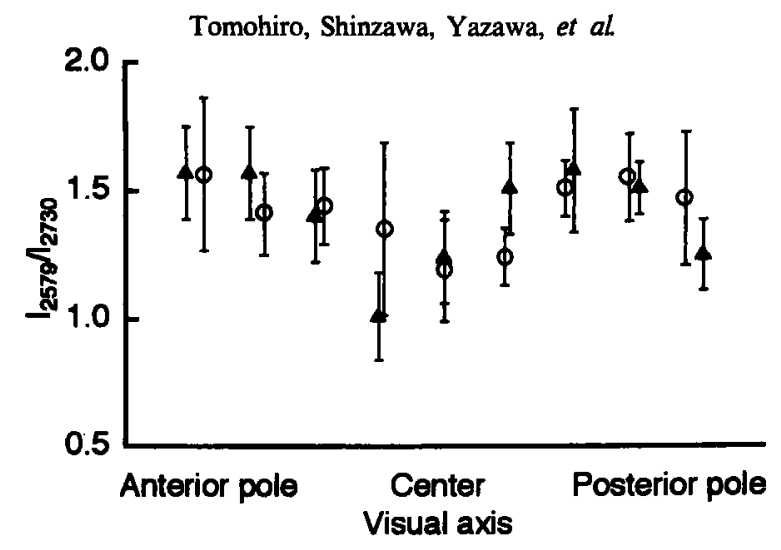

Fig. 5E.

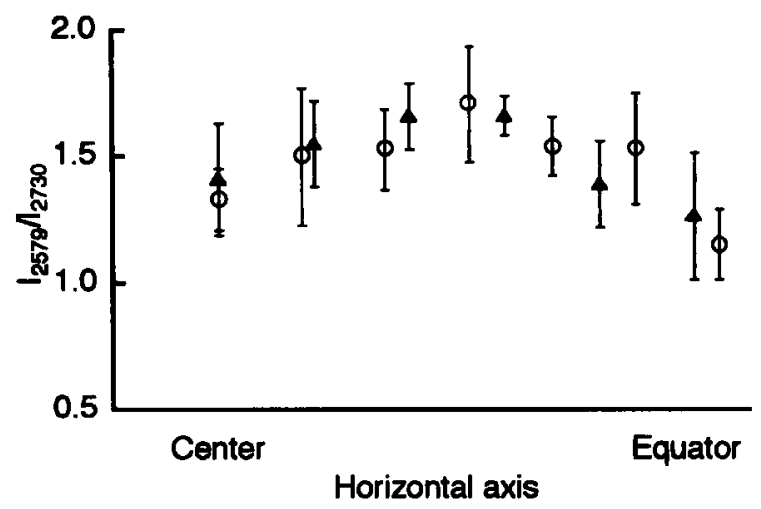

Fig. SF.

Fig. 5. The intensity ratio of Raman spectra from various positions on the lens of the L-type ( $\Delta$ ) and $N$-type (O) UPL rats. $n=5, \pm$ standard deviation.

A. The $3,390 \mathrm{~cm}^{-1} / 2,935 \mathrm{~cm}^{-1}\left(I_{3390} / I_{2935}\right)$ ratio along the visual axis of lenses from rats at 3,4 , and 6 weeks of age.

B. The $3,390 \mathrm{~cm}^{-1} / 2,935 \mathrm{~cm}^{-1}\left(I_{3390} / I_{2935}\right)$ ratio along the horizontal axis of lenses from rats at 6 weeks of age.

C. The $510 \mathrm{~cm}^{-1} / 495 \mathrm{~cm}^{-1}\left(\mathrm{I}_{510} / \mathrm{I}_{495}\right)$ ratio along the visual axis of lenses from rats at 6 weeks of age.

D. The $510 \mathrm{~cm}^{-1} / 495 \mathrm{~cm}^{-1}\left(\mathrm{I}_{510} / \mathrm{I}_{495}\right)$ ratio along the horizontal axis of lenses from rats at 6 weeks of age.

E. The $2,579 \mathrm{~cm}^{-1} / 2,730 \mathrm{~cm}^{-1}\left(\mathrm{I}_{2579} / \mathrm{I}_{2730}\right)$ ratio along the visual axis of lenses from rats at 6 weeks of age.

F. The $2,579 \mathrm{~cm}^{-1} / 2,730 \mathrm{~cm}^{-1}\left(\mathrm{I}_{2579} / \mathrm{I}_{2730}\right)$ ratio along the horizontal axis of lenses from rats at 6 weeks of age.

posterior and equator regions of the lens in the $\mathrm{L}-$ type rats.

The intensity ratio of the bands at 2,579 and $2,730 \mathrm{~cm}^{-1}\left(\mathrm{I}_{2579} / \mathrm{I}_{2730}\right)$ is indicative of the relative sulfhydryl group content of the lens ${ }^{9,14,17}$. The minimum sulfhydryl content of the L-type lens was observed in an area slightly anterior from the center of the lens (Fig. 5E). There were no alterations in the sulfhydryl content in the anterior, posterior or equator region of the L-type lenses (Figs. 5E and 5F).

\section{Discussion}

In this study, we examined the initial morphologic changes and cataract development in the Ltype UPL rat. The stage I cataract was initially observed at 2 weeks of age. Prior to classification as stage I, there were no morphologic changes and the lenses appeared to grow normally, which in contrast to the E-type UPL rat which had abnormal lens cells during the fetal period (not published). The Cts 
mouse also has cataracts in the heterozygous and homozygous state with microphthalmos only in the homozygous state ${ }^{18,19}$. However, in both $\mathrm{Cts}$ phenotypes, morphological changes are present in the fetal period ${ }^{20}$. It appeared that the initial L-type morphological changes occurred in lens fibers rather than in epithelial cells which may be similar to the sequence described in the Philly mouse ${ }^{21}$. In the lenses classified as stage $I$, the end of the lens fibers in the anterior suture region contained intracellular vacuoles and stratified epithelial cells were present in the anterior suture and equator regions. Stratification of lens epithelial cells has also been observed in other hereditary cataract models, including the UPL E-type rat ${ }^{1,221-25}$. Stratification of lens epithelial cells may be the result of abnormal interaction between epithelial cells and lens fiber cells. Marked histological changes were observed in the equator region of the stage II cataract. In addition, morphological continuity between epithelial cells and lens fibers was lost in this region. It is well known that epithelial cells elongate into lens fiber cells in the equator region of the lens. The initial change in the developing lens may be an abnormal elongation of the lens fiber cells. Similar changes were noted in the E-type UPL rat during fetal development ${ }^{1}$. Several of the L-type rats did not have a stage I cataract but went directly from a clinically normal appearance to stage II cataract. It is possible that these rats had slight microscopic changes that were not visibly detectable.

The formation of vacuoles and the rupture and liquefaction of lens fibers were considered to be the result of hydration. In the Nakano mouse (cacstarin), osmotic damage as the resumt of a deficiency of Na-K ATPase occurred in the lens and similar histological findings have been reported ${ }^{26-28}$. In the stage II and III cataracts, vacuolation and rupture of lens fiber cells were initially evident in the posterior and equator regions of the cortex. Raman spectra measurements revealed an increase in relative water content in the posterior cortex which suggested that hydration initially occurred in this area. Since water content markedly increased in the mature cataract in the UPL L-type rats (not published), it would appear that hydration spread to the entire cortex in stage IV. The Raman spectroscopic studies demonstrated that sulfhydryl $\left(\mathrm{I}_{2579} / \mathrm{I}_{2730}\right)$ was minimum and disulfide
$\left(I_{510} / I_{495}\right)$ was maximum in the lens nucleus ${ }^{15,17,29}$. The Raman spectra indicated that the lens nucleus was shifted to the anterior in the L-type rats. This may have been due to hydration in the posterior region of the lens or to the abnormal elongation of lens fibers. Posterior displacement of the nucleus has been reported in the Cts mouse ${ }^{23}$, the Ihara cataract rat $(\mathrm{ICR})^{30}$ and SCR rat $^{22}$. Displacement to the anterior appears to be unusual and may be a unique feature of cataract formation in the L-type UPL rats. The mechanism of hydration in the $\mathbf{L}$-type UPL rats in unknown. Because disruption of the lens capsule and leakage of crystallins into the aqueous humor in the stage IV lenses were also observed (data not shown), alteration of cell permeability might have occurred. In the ICR model cataract, slight superficial opacity occurred first in the equator region of the lens with posterior opacity as the next step and finally the development of a mature cataract ${ }^{31}$. The initial alterations observed in the L-type UPL rat may be different from the ICR, however, both appear to have a similar process of lens opacity and the final steps in maturation of cataract may have a common mechanism.

A decrease in sulfhydryl groups and/or increase in disulfide bonds was observed in the lenses of the ICR4, the Emory mouse ${ }^{32,33}$ and the cac-strain mouse ${ }^{9}$. These changes were considered to be related to the conversion of $2 \mathrm{SH} \rightarrow \mathrm{SS}$, which commonly occurs with age and is enhanced during cataractogenesis. However, disulfide bonds are decreased in the lens nucleus of the hereditary cataract of the SCR rat ${ }^{6}$ and it has also been reported that impaired formation of protein disulfide bonds may be related to lens opacity. There was no significant alteration in sulfhydryl groups or disulfide bonds in the L-type UPL rat. This may show multiplicity of cataract development.

In conclusion, the initial changes in the L-type UPL cataract lenses were observed in lens fibers at the anterior suture which may have been related to abnormal lens fiber elongation. Then this change extended to the equator and posterior cortex. Water content was increased in the posterior cortex of the lens, possibly related to changes in cell permeability. Hydration appeared to spread through the entire cortex of the lens. It was also indicated that the Ltype UPL rat was a good model for the study of 
human acquired cataracts.

Acknowledgements : We would like thank Dr. John E. Lund (Pharmacia \& Upjohn Inc.), Dr. Shigeharu Yokohama, Dr. Mamoru Higuchi, and Dr. Jun Hatanaka (Upjohn Pharmaceuticals Limited) for their invaluable suggestions.

\section{References}

1. Tomohiro, M, Maruyama, Y, Yazawa, K, Shinzawa, S, and Mizuno, A : The UPL rat : a new model for hereditary cataracts with two cataract formation types. Exp Eye Res 57 : 507-510, 1993.

2. Tomohiro, M, Maruyama, and $\mathbf{Y}$, Mizuno, A : Hereditary cataract rat derived from the Sprague-Dewley colony. Anim Eye Res 12 : 37-44, 1993.

3. Mizuno, A, Nozawa, $H$, Yaginuma, T, Matsuzaki, $H$, Ozaki, $\mathbf{Y}$, and Iriyama, $\mathrm{K}$ : Effect of aldose reductase inhibitor on experimental diabetic cataract monitored by laser Raman spectroscopy. Exp Eye Res 45: 185-186, 1987.

4. Mizuno, A, Kanematsu, EH, Suzuki, H, and Ihara, $\mathbf{N}$ : Laser Raman spectroscopic study of hereditary cataractous lenses in ICR/f-strain rat. Jpn J Ophthalmol 32: 281-287, 1988.

5. Mizuno, A, Nishigori, $\mathbf{H}$, and Iwatsuru $\mathbf{M}$ : Glucocorticoid-induced cataract in chick embryo monitored by Raman spectroscopy. Invest Ophthal Vis Sci $\mathbf{3 0}$ : 132-137, 1989.

6. Mizuno, A, Shumiya, S, Toshima, S, and Nakano, T : Alteration of lens disulfide bonds in newly developed hereditary cataract rat. Jpn J Ophthalmol 36: 417425, 1992.

7. Thomas, DM and Schepler, KL : Raman spectra of normal and ultraviolet-induced cataractous rabbit lens. Invest Ophthalmol Vis Sci 19 : 904-912, 1980.

8. Iriyama, K, Mizuno, A, Ozaki, Y, Itoh, K, and Matsuza$\mathrm{ki}, \mathrm{H}$ : An application of laser Raman spectroscopy to the study of a hereditary cataractous lens; on the Raman band for a diagnostic marker of cataractous signatures. Curr Eye Res 2 : 489-492, 1982.

9. Itoh, K, Ozaki, Y, Mizuno, A, and Iriyama, K : Structural changes in the lens proteins of hereditary cataracts monitored by Raman spectroscopy. Biochem 22 : 1773-1778, 1983.

10. Yu, NT and East, EJ : Laser Raman spectroscopic studies of ocular lens and its isolated protein fractions. J Biol Chem 250 : 2196-2202, 1975.

11. Yu, NT, Kuch, JFR Jr, and Askren, CC : Laser Raman spectroscopy of the lens in situ, measured in an anethesized rabbit. Curr Eye Res 1 : 615-618, 1982.

12. Mizuno, A, Ozaki, Y, Kamada, Y, Miyazaki, H, Itoh, K, and Iriyama, $\mathrm{K}$ : Direct measurement of Raman spectra of intact lens in a whole eyeball. Curr Eye Res 1 : 609-613, 1982.

13. Humason, GL: Animal Tissue Technique. 2nd ed. San Francisco: WH Freeman Co 432, 1967.
14. Ozaki, Y, Mizuno, A, Ito, K, Yoshiura, M, Iwamoto, $T$, and Iriyama, $K$ : Raman spectroscopic study of agerelated structural changes in the lens proteins of an intact lens. Biochemistry 22 : 6254-6259, 1983.

15. Yu, NT, Denagel, DC, Pruett, PL, and Kuck, JFR Jr : Disulfide bond formation in the eye lens. Proc Natl Acad Sci USA 82 : 7965-7968, 1985.

16. Ozaki, Y, Mizuno, A, Itoh, K, and Iriyama, K : Interand intramolecular disulfide bond formation and related structural changes in the lens protein, A Raman spectroscopic study in vivo of lens aging. J Biol Chem 262 15445-15551, 1987.

17. Askren, CC, Yu, NT, and Kuch, JFR Jr : Variation of the concentration of sulfhydryl along the visual axis of aging lenses by laser Raman opitic dissection technique. Exp Eye Res 29 : 647-654, 1979.

18. Ohotori, H, Yoshida, T, and Inuta, T: "Small eye and cataract", a new dominant mutation in the mouse. Exp Anim 17: 91-96, 1968.

19. Harata, M, Shoji, $\mathbf{R}$, and Semba, $\mathbf{R}$ : Genetic background and expresivity of congenital cataract in mice. Jpn J Genetics 53 : 147-152, 1978.

20. Ikeda, A, Seki, Y, Yoshii, I, and Mishima, N : An immunohistochemical study of lens development in a mutant small eye and cataractous mouse. Arch Histol Jpn $44: 237-249,1981$.

21. Uga, S, Kader, PF, and Kuwabara, T: Cytological Study of Philly Mouse Cataract. Exp Eye Res 30 : 7992, 1980.

22. Okano, T, Uga, S, Ishikawa, S, and Shumiya, S : Histopathological study of hereditary cataractous lenses in SCR strain rat. Exp Eye Res 57: 567-576, 1993.

23. Uga, $S$, Kohara, $M$, and Ishikawa, $S$ : Hereditary cataract in dominant mutant $\mathrm{Cts}$ of the mouse : morphologic study. Acta Soc Ophthalmol Jpn 85 : 895-900, 1981.

24. Zwaan, J and Williams, RM : Morphogenesis of the eye lens in a mouse strain with hereditary cataracts. J Exp Zool 169 : 407-422, 1968.

25. Zwaan, J and Williams, RM : Cataracts and abnormal proliferation of the lens epithelium in mice carrying the CatFr gene. Exp Eye Res 8: 161-167, 1969.

26. Iwata, $\mathrm{S}$ and Kinoshita, JH : Mechanism of development of hereditary cataract in mice. Invest Ophthal 10 : 504-512, 1971.

27. Hamai, Y, Fukui, HN, and Kuwabara, T : Morphology of fereditary mouse cataract. Exp Eye Res 18 : 537546, 1974.

28. Uga, S: Mechanisms of cataract formation : comparison of human cataractous lens with animal models. J Eye 2 : 239-242, 1985.

29. Barron, BC, Yu, NT, and Kuck, JFR Jr : Raman spectroscopic evaluation of aging and long-wave UV exposure in the guinea pig lens; a possible model for human aging. Exp Eye Res 46: 249-258, 1988.

30. Uga, $\mathbf{S}$ and Ihara, $\mathrm{N}$ : Morphological study of a hereditary rat cataract. Exp Eye Res 50: 665-670, 1990.

31. Nishida, S, Mizuno, K, Matsubara, A, and Kurono, $M$ : Age-related cataract in the hereditary cataract rat (ICR/ 1): development and classification. Ophthalmic Res 24: 253-259, 1992.

32. Ozaki, Y, Mizuno, A, Itoh, K, Matsushima, S, and 
Iriyama, K : Raman spectroscopic study of cataract formation : Emory mouse cataract. Appl Spectrosc 41 : 597-605, 1987.

33. Kuck, JFR and Kuck, KD: The Emory mouse cata- ract: loss of soluble protein, glutathione, protein sulfhydryl and other changes. Exp Eye Res 36: 351-362, 1983. 